\title{
Algorithms of Common Solutions to Generalized Mixed Equilibrium Problems and a System of Quasivariational Inclusions for Two Difference Nonlinear Operators in Banach Spaces
}

\author{
Nawitcha Onjai-uea ${ }^{1,2}$ and Poom Kumam ${ }^{1,2}$ \\ ${ }^{1}$ Department of Mathematics, Faculty of Science, King Mongkut's University of Technology Thonburi \\ (KMUTT), Bangmod, Bangkok 10140, Thailand \\ ${ }^{2}$ Centre of Excellence in Mathematics, CHE, Si Ayutthaya Road, Bangkok 10400, Thailand \\ Correspondence should be addressed to Poom Kumam, poom.kum@kmutt.ac.th
}

Received 11 December 2010; Accepted 3 January 2011

Academic Editor: S. Al-Homidan

Copyright (C) 2011 N. Onjai-uea and P. Kumam. This is an open access article distributed under the Creative Commons Attribution License, which permits unrestricted use, distribution, and reproduction in any medium, provided the original work is properly cited.

\begin{abstract}
We consider a new iterative algorithm for finding a common element of the set of generalized mixed equilibrium problems, the set of solutions of a system of quasivariational inclusions for two difference inverse strongly accretive operators, and common set of fixed points for strict pseudocontraction mappings in Banach spaces. Furthermore, strong convergence theorems of this method were established under suitable assumptions imposed on the algorithm parameters. The results obtained in this paper improve and extend some results in the literature.
\end{abstract}

\section{Introduction}

Equilibrium theory represents an important area of mathematical sciences such as optimization, operations research, game theory, financial mathematics, and mechanics. Equilibrium problems include variational inequalities, optimization problems, Nash equilibria problems, saddle point problems, fixed point problems, and complementarity problems as special cases; for example, see $[1,2]$ and the references therein. In the theory of variational inequalities, variational inclusions, and equilibrium problems, the development of an efficient and implementable iterative algorithm is interesting and important. The important generalization of variational inequalities, called variational inclusions, have been extensively studied and generalized in different directions to study a wide class of problems arising in mechanics, optimization, nonlinear programming, economics, finance, and applied sciences. 
Let $F: C \times C \rightarrow \mathbb{R}$ be a bifunction, let $\varphi: C \rightarrow \mathbb{R} \cup\{+\infty\}$ be a function, and let $B$ : $C \rightarrow E^{*}$ be a nonlinear mapping, where $\mathbb{R}$ is the set of real numbers. The so-called generalized mixed equilibrium problem is to find $u \in C$ such that

$$
F(u, y)+\langle B u, y-u\rangle+\varphi(y)-\varphi(u) \geq 0, \quad \forall y \in C
$$

The set of solutions to (1.1) is denoted by $\operatorname{GMEP}(F, \varphi, B)$, that is,

$$
\operatorname{GMEP}(F, \varphi, B)=\{u \in C: F(u, y)+\langle B u, y-u\rangle+\varphi(y)-\varphi(u) \geq 0, \forall y \in C\} .
$$

It is easy to see that $u$ is a solution of problem implying that $u \in \operatorname{dom} \varphi=\{u \in C \mid \varphi(u)<+\infty\}$.

If $B=0$, then the generalized mixed equilibrium problem (1.1) becomes the following mixed equilibrium problem which is to find $u \in C$ such that

$$
F(u, y)+\varphi(y)-\varphi(u) \geq 0, \quad \forall y \in C
$$

The set of solutions of (1.3) is denoted by $\operatorname{MEP}(F, \varphi)$.

If $\varphi=0$, then the generalized mixed equilibrium problem (1.1) becomes the following generalized equilibrium problem which is to find $u \in C$ such that

$$
F(u, y)+\langle B u, y-u\rangle \geq 0, \quad \forall y \in C
$$

The set of solution of (1.4) is denoted by $\operatorname{GEP}(F, B)$.

If $B=0$, then the generalized mixed equilibrium problem (1.4) becomes the following equilibrium problem is to find $u \in C$ such that

$$
F(u, y) \geq 0, \quad \forall y \in C
$$

The set of solution of (1.5) is denoted by $\mathrm{EP}(F)$. The generalized mixed equilibrium problems include fixed point problems, variational inequality problems, optimization problems, Nash equilibrium problems, and the equilibrium problem as special cases. Numerous problems in physics, optimization, and economics reduce to find a solution of (1.5). Some methods have been proposed to solve the equilibrium problem and variational inequality problems in Hilbert spaces and Banach spaces, see, for instance, [1-22] and the references therein.

Throughout this paper, let $E$ be a real Banach space with norm $\|\cdot\|$, let $E^{*}$ be the dual space of $E$, and let $C$ be a nonempty closed convex subset of $E$, and $\langle\cdot, \cdot\rangle$ denote the pairing between $E$ and $E^{*}$. Let $A_{1}, A_{2}: E \rightarrow E$ be single-valued nonlinear mappings, and let $M_{1}, M_{2}: E \rightarrow 2^{E}$ set-valued nonlinear mappings. We consider a system of quasivariational inclusions (SQVI): find $\left(x^{*}, y^{*}\right) \in E \times E$ such that

$$
\begin{aligned}
& 0 \in x^{*}-y^{*}+\rho_{1}\left(A_{1} y^{*}+M_{1} x^{*}\right), \\
& 0 \in y^{*}-x^{*}+\rho_{2}\left(A_{2} x^{*}+M_{2} y^{*}\right) .
\end{aligned}
$$

where $\rho_{1}, \rho_{2}>0$. As special cases of the problem (1.6), we have the following. 
(a) If $A_{1}=A_{2}=A$ and $M_{1}=M_{2}=M$, then the problem (1.6) is reduced to find $\left(x^{*}, y^{*}\right) \in E \times E$ such that

$$
\begin{aligned}
& 0 \in x^{*}-y^{*}+\rho_{1}\left(A y^{*}+M x^{*}\right), \\
& 0 \in y^{*}-x^{*}+\rho_{2}\left(A x^{*}+M y^{*}\right) .
\end{aligned}
$$

The problem (1.7) is called system variational inclusion problem denoted by $\operatorname{SVI}(E, A, M)$.

(b) Further, if $x^{*}=y^{*}$ in the problem (1.7), then the problem (1.7) is reduced to find $x^{*} \in E$ such that

$$
0 \in A x^{*}+M x^{*}
$$

The problem (1.8) is called variational inclusion problem denoted by $\operatorname{VI}(E, A, M)$.

Here we have examples of the variational inclusion (1.8).

If $M=\partial \delta_{C}$, where $C$ is a nonempty closed convex subset of $E$, and $\delta_{C}: E \rightarrow[0, \infty]$ is the indicator function of $C$, that is,

$$
\delta_{C}(x)= \begin{cases}0, & x \in C, \\ +\infty, & x \notin C,\end{cases}
$$

then the variational inclusion problem (1.8) is equivalent (see [23]) to finding $u \in C$ such that

$$
\langle A(u), v-u\rangle \geq 0, \quad \forall x \in C .
$$

This problem is called Hartman-Stampacchia variational inequality problem denoted by $\operatorname{VI}(C, A)$.

The generalized duality mapping $J_{q}: E \rightarrow 2^{E^{*}}$ is defined by

$$
J_{q}(x)=\left\{f \in E^{*}:\langle x, f\rangle=\|x\|^{q},\|f\|=\|x\|^{q-1}\right\}, \quad \forall x \in E .
$$

In particular, if $q=2$, the mapping $J_{2}$ is called the normalized duality mapping and, usually, written as $J_{2}=J$.

Let $U=\{x \in E:\|x\|=1\}$. A Banach space $E$ is said to be uniformly convex if, for any $\epsilon \in(0,2]$, there exists $\delta>0$ such that, for any $x, y \in U,\|x-y\| \geq \epsilon$ implies $\|(x+y) / 2\| \leq 1-\delta$.

It is known that a uniformly convex Banach space is reflexive and strictly convex. A Banach space $E$ is said to be smooth if the $\operatorname{limit}_{\lim } \rightarrow 0(\|x+t y\|-\|x\|) / t$ exists for all $x, y \in U$. It is also said to be uniformly smooth if the limit is attained uniformly for $x, y \in U$. The modulus of smoothness of $E$ is defined by

$$
\rho(\tau)=\sup \left\{\frac{1}{2}(\|x+y\|+\|x-y\|)-1: x, y \in E,\|x\|=1,\|y\|=\tau\right\},
$$


where $\rho:[0, \infty) \rightarrow[0, \infty)$ is a function. It is known that $E$ is uniformly smooth if and only if $\lim _{\tau \rightarrow 0} \rho(\tau) / \tau=0$. Let $q$ be a fixed real number with $1<q \leq 2$.

A Banach space $E$ is said to be $q$-uniformly smooth if there exists a constant $c>0$ such that $\rho(\tau) \leq c \tau^{q}$ for all $\tau>0$.

We note that $E$ is a uniformly smooth Banach space if and only if $J_{q}$ is single valued and uniformly continuous on any bounded subset of $E$. It is known that if $E$ is smooth, then $J$ is single valued, which is denoted by $j$. Typical examples of both uniformly convex and uniformly smooth Banach spaces are $L^{p}$, where $p>1$. More precisely, $L^{p}$ is $\min \{p, 2\}$ uniformly smooth for every $p>1$.

Let $T$ be a mapping from $E$ into itself. In this paper, we use $F(T)$ to denote the set of fixed points of the mapping $T$. Recall that the mapping $T$ is said to be nonexpansive if $\|T x-T y\| \leq\|x-y\|$, for all $x, y \in E$. Recall that a mapping $f: C \rightarrow C$ is called contractive if there exists a constant $\alpha \in(0,1)$ such that $\|f(x)-f(y)\| \leq \alpha\|x-y\|$, for all $x, y \in C$.

A mapping $T: C \rightarrow C$ is said to be $\lambda$-strictly pseudocontractive if there exists a constant $\lambda \in(0,1)$ such that

$$
\langle T x-T y, J(x-y)\rangle \leq\|x-y\|^{2}-\lambda\|(I-T) x-(I-T) y\|^{2}, \quad \forall x, y \in C .
$$

Recall that an operator $A$ of $E$ into itself is said to be accretive if

$$
\langle A x-A y, J(x-y)\rangle \geq 0, \quad \forall x, y \in E .
$$

For $\alpha>0$, recall that an operator $A$ of $E$ into itself is said to be $\alpha$-inverse strongly accretive if

$$
\langle A x-A y, J(x-y)\rangle \geq \alpha\|A x-A y\|^{2}, \quad \forall x, y \in E .
$$

The resolvent operator technique for solving variational inequalities and variational inclusions is interesting and important. The resolvent equation technique is used to develop powerful and efficient numerical techniques for solving various classes of variational inequalities, inclusions, and related optimization problems.

Definition 1.1. Let $M: E \rightarrow 2^{E}$ be a multivalued maximal accretive mapping. The singlevalued mapping $J_{(M, \rho)}: E \rightarrow E$, defined by

$$
J_{(M, \rho)}(u)=(I+\rho M)^{-1}(u), \quad \forall u \in E,
$$

is called the resolvent operator associated with $M$, where $\rho$ is any positive number and $I$ is the identity mapping.

Let $D$ be a subset of $C$, and let $P$ be a mapping of $C$ into $D$. Then, $P$ is said to be sunny if

$$
P(P x+t(x-P x))=P x,
$$

whenever $P x+t(x-P x) \in C$ for $x \in C$ and $t \geq 0$. A mapping $P$ of $C$ into itself is called a retraction if $P^{2}=P$. If a mapping $P$ of $C$ into itself is a retraction, then $P z=z$ for all $z \in R(P)$, 
where $R(P)$ is the range of $P$. A subset $D$ of $C$ is called a sunny nonexpansive retract of $C$ if there exists a sunny nonexpansive retraction from $C$ onto $D$.

In 2006, Aoyama et al. [24] considered the following problem: find $u \in C$ such that

$$
\langle A u, J(v-u)\rangle \geq 0, \quad \forall v \in C
$$

They proved that the variational inequality (1.18) is equivalent to a fixed point problem. The element $u \in C$ is a solution of the variational inequality (1.18) if and only if $u \in C$ satisfies the following equation:

$$
u=P_{C}(u-\lambda A u),
$$

where $\lambda>0$ is a constant and $P_{C}$ is a sunny nonexpansive retraction from $E$ onto $C$.

In order to find a solution of the variational inequality (1.18), the authors proved the following theorem in the framework of Banach spaces.

Theorem AIT (see [24]). Let E be a uniformly convex and 2-uniformly smooth Banach space, and let $C$ be a nonempty closed convex subset of $E$. Let $P_{C}$ be a sunny nonexpansive retraction from $E$ onto $C$, let $\alpha>0$, and let $A$ be an $\alpha$-inverse strongly accretive operator of $C$ into $E$ with $S(C, A) \neq \emptyset$, where

$$
S(C, A)=\left\{x^{*} \in C:\left\langle A x^{*}, j\left(x-x^{*}\right)\right\rangle \geq 0, x \in C\right\} .
$$

If $\left\{\lambda_{n}\right\}$ and $\left\{\alpha_{n}\right\}$ are chosen such that $\lambda_{n} \in\left[a, \alpha / K^{2}\right]$, for some $a>0$ and $\alpha_{n} \in[b, c]$, for some $b, c$ with $0<b<c<1$, then the sequence $\left\{x_{n}\right\}$ defined by the following manners: $x_{1}-x \in C$ and

$$
x_{n+1}=\alpha_{n} x_{n}+\left(1-\alpha_{n}\right) P_{C}\left(x_{n}-\lambda_{n} A x_{n}\right)
$$

converges weakly to some element $z$ of $S(C, A)$, where $K$ is the 2-uniformly smoothness constant of $E$ and $P_{C}$ is a sunny nonexpansive retraction.

Motivated by Aoyama et al. [24] and also Ceng et al. [25], Qin et al. [26] and Yao et al. [27] considered the following general system of variational inequalities: let $C$ be nonempty closed convex subset of a real Banach space E. For given two operators $A, B: C \rightarrow E$, we consider the problem of finding $\left(x^{*}, y^{*}\right) \in C \times C$ such that

$$
\begin{array}{ll}
\left\langle\lambda A y^{*}+x^{*}-y^{*}, j\left(x-x^{*}\right)\right\rangle \geq 0, & \forall x \in C, \\
\left\langle\mu B x^{*}+y^{*}-x^{*}, j\left(x-y^{*}\right)\right\rangle \geq 0, & \forall x \in C,
\end{array}
$$

where $\lambda$ and $\mu$ are two positive real numbers. This system is called the system of general variational inequalities in a real Banach space. If we add up the requirement that $A=B$, then the problem (1.22) is reduced to the system (1.23) below. Find $\left(x^{*}, y^{*}\right) \in C \times C$ such that

$$
\begin{array}{ll}
\left\langle\lambda A y^{*}+x^{*}-y^{*}, j\left(x-x^{*}\right)\right\rangle \geq 0, & \forall x \in C, \\
\left\langle\mu A x^{*}+y^{*}-x^{*}, j\left(x-y^{*}\right)\right\rangle \geq 0, & \forall x \in C .
\end{array}
$$


For the class of nonexpansive mappings, one classical way to study nonexpansive mappings is to use contractions to approximate a nonexpansive mapping [28, 29]. More precisely, take $t \in(0,1)$ and define a contraction $T_{t}: C \rightarrow C$ by

$$
T_{t} x=t u+(1-t) T x, \quad \forall x \in C,
$$

where $u \in C$ is a fixed point and $T: C \rightarrow C$ is a nonexpansive mapping. The Banach contraction mapping principle guarantees that $T_{t}$ has a unique fixed point $x_{t}$ in $C$, that is,

$$
x_{t}=t u+(1-t) T x_{t}
$$

It is unclear, in general, what the behavior of $x_{t}$ is as $t \rightarrow 0$, even if $T$ has a fixed point. However, in the case of $T$ having a fixed point, Browder [28] proved that if $E$ is a Hilbert space, then $x_{t}$ converges strongly to a fixed point of $T$. Reich [29] extended Browder s result to the setting of Banach spaces and proved that if $E$ is a uniformly smooth Banach space, then $x_{t}$ converges strongly to a fixed point of $T$ and the limit defines the (unique) sunny nonexpansive retraction from $C$ onto $F(T)$.

Reich [29] showed that if $E$ is uniformly smooth and $D$ is the fixed point set of a nonexpansive mapping from $C$ into itself, then there is a unique sunny nonexpansive retraction from $C$ onto $D$, and it can be constructed as follows.

Proposition 1.2 (see [29]). Let $E$ be a uniformly smooth Banach space, and let $T: C \rightarrow C$ be a nonexpansive mapping such that $F(T) \neq \emptyset$. For each fixed $u \in C$ and every $t \in(0,1)$, the unique fixed point $x_{t} \in C$ of the contraction $C \ni x \mapsto t u+(1-t) T x$ converges strongly as $t \rightarrow 0$ to a fixed point of T. Define $P: C \rightarrow D$ by $P u=s-\lim _{t \rightarrow 0} x_{t}$. Then $P$ is the unique sunny nonexpansive retract from $C$ onto $D$; that is, $P$ satisfies the following property:

$$
\langle u-P u, J(y-P u)\rangle \leq 0, \quad \forall u \in C, y \in D
$$

Note that we use $P u=s-\lim _{t \rightarrow 0} x_{t}$ to denote strong convergence to $P_{u}$ of the net $\left\{x_{t}\right\}$ as $t \rightarrow 0$.

In 2010, Qin et al. [16] considered the generalized equilibrium problem and a strictly pseudocontractive mapping to prove the following result.

\section{Theorem QCK [see [16]]}

Let $C$ be a nonempty closed convex subset of a real Hilbert space $H$. Let $F$ be a bifunction from $C \times C$ to $\mathbb{R}$ which satisfies (A1)-(A4), and let $B: C \rightarrow H$ be a $\lambda$-inverse strongly monotone mapping. Let $S: C \rightarrow C$ be a $k$-strict pseudocontraction, let $A_{1}: C \rightarrow H$ be an $\alpha$ inverse strongly monotone mapping, and let $A_{2}: C \rightarrow H$ be a $\beta$-inverse strongly monotone mapping. Assume that $\mathcal{F}:=E P(F, B) \cap \operatorname{VI}\left(C, A_{1}\right) \cap \operatorname{VI}\left(C, A_{2}\right) \cap F(S)$ is nonempty. Let $\left\{\alpha_{n}\right\}$ and $\left\{\beta_{n}\right\}$ be sequences in $(0,1)$. Let $\left\{t_{n}\right\}$ be a sequence in $(0,2 \alpha)$, let $\left\{s_{n}\right\}$ be a sequence in 
$(0,2 \beta)$, and let $\left\{r_{n}\right\}$ be a sequence in $(0,2 \lambda)$. Let $\left\{x_{n}\right\}$ be a sequence generated in the following manner:

$$
\begin{aligned}
& x_{1} \in C \text {, chosen arbitrary, } \\
& u_{n} \in C \text { such that } F\left(u_{n}, u\right)+\left\langle B x_{n}, u-u_{n}\right\rangle+\frac{1}{r_{n}}\left\langle u-u_{n}, u_{n}-x_{n}\right\rangle \geq 0, \quad \forall u \in C, \\
& z_{n}=Q_{C}\left(u_{n}-s_{n} A_{2} u_{n}\right), \\
& y_{n}=Q_{C}\left(z_{n}-t_{n} A_{1} z_{n}\right),
\end{aligned}
$$

Assume that the sequences $\left\{\alpha_{n}\right\},\left\{\beta_{n}\right\},\left\{t_{n}\right\},\left\{s_{n}\right\}$, and $\left\{r_{n}\right\}$ satisfy the following restrictions:

(a) $0<a \leq \alpha_{n} \leq a^{\prime}<1$;

(b) $0<k \leq \beta_{n} \leq b<1$;

(c) $0<c \leq r_{n} \leq d<2 \lambda, 0<c^{\prime} \leq s_{n} \leq d^{\prime}<2 \beta$, and $0<c^{\prime \prime} \leq t_{n} \leq d^{\prime \prime}<2 \alpha$.

Then the sequence $\left\{x_{n}\right\}$ generated in (1.27) converges weakly to some point $\bar{x} \in \mathcal{F}$, where $\bar{x}=\lim _{n \rightarrow \infty} Q_{\bar{q}} x_{n}$ and $Q_{\bar{q}}$ is the projection of $H$ onto set $\mathcal{F}$.

Recently, W. Kumam and P. Kumam [12] introduced a new viscosity relaxed extragradient approximation method which is based on the so-called relaxed extragradient method and viscosity approximation method for finding the common element of the set of fixed points of a nonexpansive mapping, the set of solutions of an equilibrium problem, and the solutions of the variational inequality problem for two inverse strongly monotone mappings in Hilbert spaces. Katchang et al. [13] introduced a new iterative scheme for finding solutions of a variational inequality for inverse strongly accretive mappings with a viscosity approximation method in Banach spaces. They prove a strong convergence theorem in Banach spaces under some parameters controlling conditions. Katchang and Kumam [30], further extended the work of [26] and constructed a viscosity iterative scheme for finding solutions of a general system of variational inequalities (1.22) for two inverse-strongly accretive operators with a viscosity of modified extragradient methods and solutions of fixed point problems involving the nonexpansive mapping in Banach spaces. Then, they obtained strong convergence theorems for a solution of the system of general variational inequalities (1.22) in the frame work of Banach spaces.

Very recently, Qin et al. [31] considered the problem of finding the solutions of a general system of variational inclusion (1.6) with $\alpha$-inverse strongly accretive mappings. To be more precise, they obtained the following results.

Lemma 1.3 (see [31]). For given $\left(x^{*}, y^{*}\right) \in E \times E$, where $y^{*}=J_{M_{2}, \rho_{2}}\left(x^{*}-\rho_{2} A_{2} x^{*}\right),\left(x^{*}, y^{*}\right)$ is a solution of the problem (1.1) if and only if $x^{*}$ is a fixed point of the mapping $\widetilde{Q}$ defined by

$$
\widetilde{Q}(x)=J_{\left(M_{1}, \rho_{1}\right)}\left[J_{\left(M_{2}, \rho_{2}\right)}\left(x-\rho_{2} A_{2} x\right)-\rho_{1} A_{1} J_{\left(M_{2}, \rho_{2}\right)}\left(x-\rho_{2} A_{2} x\right)\right] .
$$

Theorem QCCK (see [31]). Let E be a uniformly convex and 2-uniformly smooth Banach space with the smooth constant $K$. Let $M_{i}: E \rightarrow 2^{E}$ be a maximal monotone mapping and let $A_{i}: E \rightarrow E$ be a $\gamma_{i}$-inverse strongly accretive mapping, respectively, for each $i=1,2$. Let $T: E \rightarrow E$ be a $\lambda$-strict 
pseudocontraction with fixed point. Define a mapping $S$ by $S x=\left(1-\left(\lambda / K^{2}\right)\right) x+\left(\lambda / K^{2}\right) T x$, for all $x \in E$. Assume that $\Theta=F(T) \cap F(\widetilde{Q}) \neq \emptyset$, where $\widetilde{Q}$ is defined as Lemma 1.3. Let $x_{1}=u \in E$, and let $\left\{x_{n}\right\}$ be a sequence generated by

$$
\begin{gathered}
z_{n}=J_{\left(M_{2}, \rho_{2}\right)}\left(x_{n}-\rho_{2} A_{2} x_{n}\right), \\
y_{n}=J_{\left(M_{1}, \rho_{1}\right)}\left(z_{n}-\rho_{1} A_{1} z_{n}\right), \\
x_{n+1}=\alpha_{n} u+\beta_{n} x_{n}+\left(1-\beta_{n}-\alpha_{n}\right)\left[\mu S x_{n}+(1-\mu) y_{n}\right], \quad \forall n \geq 1,
\end{gathered}
$$

where $\mu \in(0,1), \rho_{1} \in\left(0, \gamma_{1} / K^{2}\right], \rho_{2} \in\left(0, \gamma_{2} / K^{2}\right]$ and $\left\{\alpha_{n}\right\}$ and $\left\{\beta_{n}\right\}$ are sequences in $(0,1)$. If the control consequences $\left\{\alpha_{n}\right\}$ and $\left\{\beta_{n}\right\}$ satisfy the following restrictions

(C1) $0<\liminf _{n \rightarrow \infty} \beta_{n} \leq \limsup _{n \rightarrow \infty} \beta_{n}<1$ and

(C2) $\lim _{n \rightarrow \infty} \alpha_{n}=0$ and $\sum_{n=0}^{\infty} \alpha_{n}=\infty$,

then $\left\{x_{n}\right\}$ converges strongly to $x^{*}=P_{\Theta} u$, where $P_{\Theta}$ is the sunny nonexpansive retraction from $E$ onto $\Theta$ and $\left(x^{*}, y^{*}\right)$, where $y^{*}=J_{\left(M_{2}, \rho_{2}\right)}\left(x^{*}-\rho_{2} A_{2} x^{*}\right)$, is solution to the problem (1.6).

In this paper, motivated by the above results and the iterative schemes considered in Qin et al. [31,32] and Katchang and Kumam [30], we present a new general iterative scheme so call a relaxed extragradient-type method for finding a common element of the set of solutions for generalized mixed equilibrium problems, the set of solutions of common system of variational inclusions for two inverse-strongly accretive operators and common set of fixed points for a strict pseudocontraction in 2-uniformly smooth Banach spaces. Then, we prove the strong convergence of the proposed iterative method under some suitable conditions. The results presented in this paper extend and improve the results of Qin et al. [31,32] and many authors.

\section{Preliminaries}

First, we recall some definitions and conclusions.

For solving the generalized mixed equilibrium problem, let us give the following assumptions for the bifunction $F: C \times C \rightarrow \mathbb{R} ; \varphi: C \rightarrow \mathbb{R}$ is convex and lower semicontinuous; the nonlinear mapping $B: C \rightarrow E^{*}$ is continuous and monotone satisfying the following conditions:

(A1) $F(x, x)=0$ for all $x \in C$;

(A2) $F$ is monotone, that is, $F(x, y)+F(y, x) \leq 0$ for all $x, y \in C$;

(A3) for each $x, y, z \in C, \lim _{t \downarrow 0} F(t z+(1-t) x, y) \leq F(x, y)$;

(A4) for each $x \in C, y \mapsto F(x, y)$ is convex and lower semicontinuous;

(B1) for each $x \in E$ and $r>0$, there exist abounded subset $D_{x} \subseteq C$ and $y_{x} \in C$ such that for any $z \in C \backslash D_{x}$,

$$
F\left(z, y_{x}\right)+\varphi\left(y_{x}\right)-\varphi(z)+\frac{1}{r}\left\langle y_{x}-z, J z-J x\right\rangle<0
$$

(B2) $C$ is a bounded set. 
Lemma 2.1 (see [33, Lemma 2.7]). Let $C$ be a closed convex subset of smooth, strictly convex, and reflexive Banach space $E$, let $F: C \times C \rightarrow \mathbb{R}$ be a bifunction satisfying (A1)-(A4), and let $r>0$ and $x \in E$. Then, there exists $z \in C$ such that

$$
F(z, y)+\frac{1}{r}\langle y-z, J z-J x\rangle \geq 0, \quad \forall y \in C
$$

Motivated by the work of Combettes and Hirstoaga [34] in a Hilbert space and Takahashi and Zembayashi [33] in a Banach space, Zhang [35] and also authors of [36] obtained the following lemma.

Lemma 2.2 (see [35]). Let $C$ be nonempty closed convex subset of a uniformly smooth, strictly convex and reflexive Banach space $E$. Let $B: C \rightarrow E^{*}$ be a continuous and monotone mapping, let $\varphi: C \rightarrow \mathbb{R}$ be a lower semicontinuous and convex function, and let $F: C \times C \rightarrow \mathbb{R}$ be a bifunction satisfying (A1)-(A4). For $r>0$ and $x \in E$, there exists $u \in C$ such that

$$
F(u, y)+\langle B u, y-u\rangle+\varphi(y)-\varphi(u)+\frac{1}{r}\langle y-u, J u-J x\rangle, \quad \forall y \in C
$$

Define a mapping $K_{r}: C \rightarrow C$ as follows:

$$
K_{r}(x)=\left\{u \in C: F(u, y)+\langle B u, y-u\rangle+\varphi(y)-\varphi(u)+\frac{1}{r}\langle y-u, J u-J x\rangle \geq 0, \forall y \in C\right\}
$$

for all $x \in C$. Then, the following conclusions hold:

(1) $K_{r}$ is single valued;

(2) $K_{r}$ is firmly nonexpansive; that is, for any $x, y \in E,\left\langle K_{r} x-K_{r} y, J K_{r} x-J K_{r} y\right\rangle \leq\left\langle K_{r} x-\right.$ $\left.K_{r} y, J x-J y\right\rangle$

(3) $F\left(K_{r}\right)=\operatorname{GMEP}(F, \varphi, B)$;

(4) $\operatorname{GMEP}(F, \varphi, B)$ is closed and convex.

Lemma 2.3 (see [37]). Assume that $\left\{a_{n}\right\}$ is a sequence of nonnegative real numbers such that

$$
a_{n+1} \leq\left(1-\alpha_{n}\right) a_{n}+\delta_{n}, \quad n \geq 0,
$$

where $\left\{\alpha_{n}\right\}$ is a sequence in $(0,1)$ and $\left\{\delta_{n}\right\}$ is a sequence in $\mathbb{R}$ such that

(1) $\sum_{n=1}^{\infty} \alpha_{n}=\infty$;

(2) $\lim \sup _{n \rightarrow \infty} \delta_{n} / \alpha_{n} \leq 0$ or $\sum_{n=1}^{\infty}\left|\delta_{n}\right|<\infty$.

Then, $\lim _{n \rightarrow \infty} a_{n}=0$.

Lemma 2.4 (see [38]). Let $\left\{x_{n}\right\}$ and $\left\{y_{n}\right\}$ be bounded sequences in a Banach space $X$, and let $\left\{\beta_{n}\right\}$ be a sequence in $[0,1]$ with $0<\liminf _{n \rightarrow \infty} \beta_{n} \leq \lim \sup _{n \rightarrow \infty} \beta_{n}<1$. Suppose that $x_{n+1}=\left(1-\beta_{n}\right) y_{n}+$ $\beta_{n} x_{n}$ for all integers $n \geq 0$ and $\lim \sup _{n \rightarrow \infty}\left(\left\|y_{n+1}-y_{n}\right\|-\left\|x_{n+1}-x_{n}\right\|\right) \leq 0$. Then, $\lim _{n \rightarrow \infty}\left\|y_{n}-x_{n}\right\|$ $=0$. 
Lemma 2.5 (see [23]). The resolvent operator $J_{M, \rho}$ associated with $M$ is single valued and nonexpansive for all $\rho>0$.

Lemma 2.6 (see [23]). Let $u \in E$. Then $u$ is a solution of variational inclusion (1.6) if and only if $u=J_{M, \rho}(u-\rho A u)$, for all $\rho>0$, that is,

$$
V I(E, A, M)=F\left(J_{(M, \rho)}(I-\rho A)\right), \quad \forall \rho>0,
$$

where $\operatorname{VI}(E, A, M)$ denotes the set of solutions to the problem (1.8).

The following results describe a characterization of sunny nonexpansive retractions on a smooth Banach space.

Proposition 2.7 (see [39]). Let $E$ be a smooth Banach space, and let $C$ be a nonempty subset of $E$. Let $P: E \rightarrow C$ be a retraction, and let $J$ be the normalized duality mapping on $E$. Then the following are equivalent:

(1) $P$ is sunny and nonexpansive;

(2) $\|P x-P y\|^{2} \leq\langle x-y, J(P x-P y)\rangle$, for all $x, y \in C$;

(3) $\langle x-P x, J(y-P x)\rangle \leq 0$, for all $x \in E, y \in C$.

Proposition 2.8 (see [40]). Let $C$ be a nonempty closed convex subset of a uniformly convex and uniformly smooth Banach space $E$, and let $T$ be a nonexpansive mapping of $C$ into itself with $F(T) \neq \emptyset$. Then the set $F(T)$ is a sunny nonexpansive retract of $C$.

Lemma 2.9 (see [31]). Let $E$ be a strictly convex Banach space. Let $T_{1}$ and $T_{2}$ be two nonexpansive mappings from $E$ into itself with a common fixed point. Define a mapping $S$ by

$$
S x=\lambda T_{1} x+(1-\lambda) T_{2} x, \quad \forall x \in E,
$$

where $\lambda$ is a constant in $(0,1)$. Then $S$ is nonexpansive and $F(S)=F\left(T_{1}\right) \cap F\left(T_{2}\right)$.

Lemma 2.10 (see [28]). Let E be a uniformly convex Banach space, and let $S$ be a nonexpansive mapping on $E$. Then $I-S$ is demiclosed at zero.

Lemma 2.11 (see [31]). Let $E$ be a real 2-uniformly smooth Banach space, and let $T: E \rightarrow E$ be a $\lambda$-strict pseudocontraction. Then $S:=\left(1-\lambda / K^{2}\right) I+\lambda / K^{2} T$ is nonexpansive and $F(T)=F(S)$.

Lemma 2.12 (see [41]). Let E be a real 2-uniformly smooth Banach space with the best smooth constant $K$. Then the following inequality holds:

$$
\|x+y\|^{2} \leq\|x\|^{2}+2\langle y, J x\rangle+2\|K y\|^{2}, \quad \forall x, y \in E .
$$

Lemma 2.13. In a real Banach space E, the following inequality holds:

$$
\|x+y\|^{2} \leq\|x\|^{2}+2\langle y, J(x+y)\rangle, \quad \forall x, y \in E
$$


Lemma 2.14. Let $C$ be a nonempty closed convex subset of a real 2-uniformly smooth Banach space $E$ with the smooth constant $K$. Let the mapping $A: E \rightarrow E$ be a $\gamma$-inverse-strongly accretive mapping. If $\rho \in\left(0, \gamma / K^{2}\right)$, then $I-\rho A$ is nonexpansive.

Proof. For any $x, y \in C$, from Lemma 2.12, one has

$$
\begin{aligned}
\|(I-\rho A) x-(I-\rho A) y\|^{2} & =\|(x-y)-\rho(A x-A y)\|^{2} \\
& \leq\|x-y\|^{2}-2 \rho\langle A x-A y, J(x-y)\rangle+2 K^{2} \rho_{1}^{2}\|A x-A y\|^{2} \\
& \leq\|x-y\|^{2}-2 \rho \gamma\|A x-A y\|^{2}+2 K^{2} \rho^{2}\|A x-A y\|^{2} \\
& =\|x-y\|^{2}-2 \rho\left(\gamma-K^{2} \rho\right)\|A x-A y\|^{2} \\
& \leq\|x-y\|^{2},
\end{aligned}
$$

which implies that the mapping $I-\rho A$ is nonexpansive.

\section{Main Result}

In this section, we prove a strong convergence theorem for finding a common element of the set of fixed points of strict pseudocontraction mappings, the set of solutions of a generalized mixed equilibrium problem, and the set of solutions of system of quasivariational inclusion problem for an inverse-strongly monotone mapping in a uniformly convex and 2-uniformly smooth Banach space.

Theorem 3.1. Let E be a uniformly convex and 2-uniformly smooth Banach space with the smooth constant $K$. Let $M_{i}: E \rightarrow 2^{E}$ be a maximal monotone mapping, and let $A_{i}: E \rightarrow E$ be a $\gamma_{i^{-}}$ inverse strongly accretive mapping, respectively, for each $i=1,2$. Let $F$ be a bifunction of $C \times C$ into real numbers $\mathbb{R}$ satisfying (A1)-(A4). Let $B: E \rightarrow E^{*}$ be a continuous and monotone mapping and let $\varphi: C \rightarrow \mathbb{R} \cup\{+\infty\}$ be a proper lower semicontinuous and convex function. Let $f$ be a contraction of E into itself with coefficient $\alpha \in(0,1)$. Let $S: E \rightarrow E$ be a $\lambda$-strict pseudocontraction with a fixed point. Define a mapping $S_{k}$ by $S_{k} x=k x+(1-k) S x$, for all $x \in E$. Assume that $\Omega:=F(S) \cap F(\widetilde{Q}) \cap \operatorname{GMEP}(F, \varphi, B) \neq \emptyset$, where $\widetilde{Q}$ is defined as in Lemma 1.3. Assume that either (B1) or (B2) holds. Let $\left\{x_{n}\right\}$ be a sequence generated by $x_{1} \in E$ and

$$
\begin{gathered}
F\left(u_{n}, y\right)+\left\langle B u_{n}, y-u_{n}\right\rangle+\varphi(y)-\varphi\left(u_{n}\right)+\frac{1}{r}\left\langle y-u_{n}, J u_{n}-J x_{n}\right\rangle \geq 0, \quad \forall y \in C, \\
y_{n}=J_{M_{2}, \rho_{2}}\left(u_{n}-\rho_{2} A_{2} u_{n}\right), \\
v_{n}=J_{M_{1}, \rho_{1}}\left(y_{n}-\rho_{1} A_{1} y_{n}\right), \\
x_{n+1}=\alpha_{n} f\left(x_{n}\right)+\beta_{n} x_{n}+\gamma_{n}\left[\mu_{1} S_{k} x_{n}+\left(1-\mu_{1}\right) v_{n}\right],
\end{gathered}
$$

for every $n \geq 1$, where $\left\{\alpha_{n}\right\},\left\{\beta_{n}\right\}$ and $\left\{\gamma_{n}\right\}$ are sequences in $[0,1], \mu_{1} \in[0,1), \rho_{1} \in\left(0, \gamma_{1} / K^{2}\right]$, $\rho_{2} \in\left(0, \gamma_{2} / K^{2}\right]$ and $r>0$. If the control sequences satisfy the following restrictions: 
(i) $\alpha_{n}+\beta_{n}+\gamma_{n}=1$,

(ii) $\sum_{n=0}^{\infty} \alpha_{n}=\infty$ and $\lim _{n \rightarrow \infty} \alpha_{n}=0$,

(iii) $0<\liminf _{n \rightarrow \infty} \beta_{n} \leq \lim \sup _{n \rightarrow \infty} \beta_{n}<1$,

then $\left\{x_{n}\right\}$ converges strongly to $\bar{x} \in \Omega$, where $\bar{x}=P_{\Omega} f(\bar{x}), P_{\Omega}$ is the sunny nonexpansive retraction from $E$ onto $\Omega$ and $(\bar{x}, \bar{y})$ is solution to the problem $(1.6)$, where $\bar{y}=J_{\left(M_{2}, \rho_{2}\right)}\left(\bar{x}-\rho_{2} A_{2} \bar{x}\right)$.

Proof. Let $H\left(u_{n}, y\right)=F\left(u_{n}, y\right)+\left\langle B u_{n}, y-u_{n}\right\rangle+\varphi(y)-\varphi\left(u_{n}\right), y \in C$,

$$
K_{r}=\left\{u \in C: H\left(u_{n}, y\right)+\frac{1}{r}\left\langle y-u_{n}, J u_{n}-J x_{n}\right\rangle \geq 0, \forall y \in C\right\}
$$

First, from condition $\rho_{1} \in\left(0, \gamma_{1} / K^{2}\right), \rho_{2} \in\left(0, \gamma_{2} / K^{2}\right)$ and Lemma 2.14 , we have that the mappings $I-\rho_{1} A_{1}$ and $I-\rho_{2} A_{2}$ are nonexpansive.

We claim that $\left\{x_{n}\right\}$ is bounded. Taking $\bar{x} \in \Omega$, one has

$$
\bar{x}=J_{\left(M_{1}, \rho_{1}\right)}\left[J_{\left(M_{2}, \rho_{2}\right)}\left(\bar{x}-\rho_{2} A_{2} \bar{x}\right)-\rho_{1} A_{1} J_{\left(M_{2}, \rho_{2}\right)}\left(\bar{x}-\rho_{2} A_{2} \bar{x}\right)\right] .
$$

Putting $\bar{y}=J_{\left(M_{2}, \rho_{2}\right)}\left(\bar{x}-\rho_{2} A_{2} \bar{x}\right)$, one sees that

$$
\bar{x}=J_{\left(M_{1}, \rho_{1}\right)}\left(\bar{y}-\rho_{1} A_{1} \bar{y}\right) .
$$

Since $\bar{x}=K_{r} \bar{x}$ and $K_{r}$ is nonexpansive mapping, we have

$$
\left\|u_{n}-\bar{x}\right\| \leq\left\|K_{r} x_{n}-K_{r} \bar{x}\right\| \leq\left\|x_{n}-\bar{x}\right\| .
$$

From the fact that $J_{\left(M_{2}, \rho_{2}\right)}$ and $I-\rho_{2} A_{2}$ are nonexpansive mappings, we get

$$
\begin{aligned}
\left\|y_{n}-\bar{y}\right\| & =\left\|J_{\left(M_{2}, \rho_{2}\right)}\left(u_{n}-\rho_{2} A_{2} u_{n}\right)-J_{\left(M_{2}, \rho_{2}\right)}\left(\bar{x}-\rho_{2} A_{2} \bar{x}\right)\right\| \\
& \leq\left\|\left(u_{n}-\rho_{2} A_{2} u_{n}\right)-\left(\bar{x}-\rho_{2} A_{2} \bar{x}\right)\right\| \\
& =\left\|\left(I-\rho_{2} A_{2}\right) u_{n}-\left(I-\rho_{2} A_{2}\right) \bar{x}\right\| \\
& \leq\left\|u_{n}-\bar{x}\right\| \leq\left\|x_{n}-\bar{x}\right\| .
\end{aligned}
$$

Similar to the above, from the fact that $J_{\left(M_{1}, \rho_{1}\right)}$ and $I-\rho_{1} A_{1}$ are nonexpansive mappings, we also have

$$
\left\|v_{n}-\bar{x}\right\| \leq\left\|y_{n}-\bar{y}\right\| \leq\left\|x_{n}-\bar{x}\right\|
$$


From $S_{k}$ being nonexpansive and putting $e_{n}=\mu_{1} S_{k} x_{n}+\left(1-\mu_{1}\right) v_{n}$, we have

$$
\begin{aligned}
\left\|e_{n}-\bar{x}\right\| & =\left\|\mu_{1} S_{k}\left(x_{n}-\bar{x}\right)+\left(1-\mu_{1}\right)\left(v_{n}-\bar{x}\right)\right\| \\
& \leq \mu_{1}\left\|S_{k} x_{n}-\bar{x}\right\|+\left(1-\mu_{1}\right)\left\|v_{n}-\bar{x}\right\| \\
& =\mu_{1}\left\|S_{k} x_{n}-S_{k} \bar{x}\right\|+\left(1-\mu_{1}\right)\left\|x_{n}-\bar{x}\right\| \\
& \leq \mu_{1}\left\|x_{n}-\bar{x}\right\|+\left(1-\mu_{1}\right)\left\|x_{n}-\bar{x}\right\|=\left\|x_{n}-\bar{x}\right\| .
\end{aligned}
$$

From (3.1), (3.8), and $\alpha_{n}+\beta_{n}+\gamma_{n}=1$, we note that

$$
\begin{aligned}
\left\|x_{n+1}-\bar{x}\right\| & =\left\|\alpha_{n}\left(f\left(x_{n}\right)-\bar{x}\right)+\beta_{n}\left(x_{n}-\bar{x}\right)+\gamma_{n}\left(e_{n}-\bar{x}\right)\right\| \\
& \leq \alpha_{n}\left\|f\left(x_{n}\right)-\bar{x}\right\|+\beta_{n}\left\|x_{n}-\bar{x}\right\|+\gamma_{n}\left\|e_{n}-\bar{x}\right\| \\
& \leq \alpha_{n}\left\|f\left(x_{n}\right)-f(\bar{x})\right\|+\alpha_{n}\|f(\bar{x})-\bar{x}\|+\beta_{n}\left\|x_{n}-\bar{x}\right\|+\gamma_{n}\left\|e_{n}-\bar{x}\right\| \\
& \leq \alpha_{n} \alpha\left\|x_{n}-\bar{x}\right\|+\alpha_{n}\|f(\bar{x})-\bar{x}\|+\beta_{n}\left\|x_{n}-\bar{x}\right\|+\gamma_{n}\left\|x_{n}-\bar{x}\right\| \\
& =\alpha_{n} \alpha\left\|x_{n}-\bar{x}\right\|+\alpha_{n}\|f(\bar{x})-\bar{x}\|+\left(1-\alpha_{n}\right)\left\|x_{n}-\bar{x}\right\| \\
& =\left(1-(1-\alpha) \alpha_{n}\right)\left\|x_{n}-\bar{x}\right\|+(1-\alpha) \alpha_{n} \frac{\|f(\bar{x})-\bar{x}\|}{1-\alpha},
\end{aligned}
$$

for every $n \in \mathbb{N}$. It follows by mathematical induction that

$$
\left\|x_{n+1}-\bar{x}\right\| \leq \max \left\{\left\|x_{1}-\bar{x}\right\|, \frac{\|f(\bar{x})-\bar{x}\|}{1-\alpha}\right\}
$$

This shows that the sequence $\left\{x_{n}\right\}$ is bounded, so are $\left\{u_{n}\right\},\left\{v_{n}\right\}$, and $\left\{y_{n}\right\}$.

We claim that $\left\|x_{n+1}-x_{n}\right\| \rightarrow 0$ as $n \rightarrow \infty$.

From algorithm (3.1), we have

$$
\begin{aligned}
\left\|y_{n+1}-y_{n}\right\| & =\left\|J_{M_{2}, \rho_{2}}\left(u_{n+1}-\rho_{2} A_{2} u_{n+1}\right)-J_{M_{2}, \rho_{2}}\left(u_{n}-\rho_{2} A_{2} u_{n}\right)\right\| \\
& \leq\left\|\left(u_{n+1}-\rho_{2} A_{2} u_{n+1}\right)-\left(u_{n}-\rho_{2} A_{2} u_{n}\right)\right\| \\
& \leq\left\|u_{n+1}-u_{n}\right\| \\
& =\left\|K_{r} x_{n+1}-K_{r} x_{n}\right\| \leq\left\|x_{n+1}-x_{n}\right\| .
\end{aligned}
$$

Similarly, we get $\left\|v_{n+1}-v_{n}\right\| \leq\left\|y_{n+1}-y_{n}\right\| \leq\left\|x_{n+1}-x_{n}\right\|$. 
From $e_{n}=\mu_{1} S_{k} x_{n}+\left(1-\mu_{1}\right) v_{n}$, we have

$$
\begin{aligned}
\left\|e_{n+1}-e_{n}\right\| & =\left\|\mu_{1} S_{k} x_{n+1}+\left(1-\mu_{1}\right) v_{n+1}-\left(\mu_{1} S_{k} x_{n}+\left(1-\mu_{1}\right) v_{n}\right)\right\| \\
& =\left\|\mu_{1}\left(S_{k} x_{n+1}-S_{k} x_{n}\right)+\left(1-\mu_{1}\right)\left(v_{n+1}-v_{n}\right)\right\| \\
& \leq \mu_{1}\left\|S_{k} x_{n+1}-S_{k} x_{n}\right\|+\left(1-\mu_{1}\right)\left\|v_{n+1}-v_{n}\right\| \\
& \leq \mu_{1}\left\|x_{n+1}-x_{n}\right\|+\left(1-\mu_{1}\right)\left\|x_{n+1}-x_{n}\right\|=\left\|x_{n+1}-x_{n}\right\| .
\end{aligned}
$$

Putting $l_{n}=\left(x_{n+1}-\beta_{n} x_{n}\right) /\left(1-\beta_{n}\right)$, for all $n \geq 1$. That is,

$$
x_{n+1}=\left(1-\beta_{n}\right) l_{n}+\beta_{n} x_{n} .
$$

One sees that

$$
\begin{aligned}
l_{n+1}-l_{n} & =\frac{\alpha_{n+1} f\left(x_{n+1}\right)+\gamma_{n+1} e_{n+1}}{1-\beta_{n+1}}-\frac{\alpha_{n} f\left(x_{n}\right)+\gamma_{n} e_{n}}{1-\beta_{n}} \\
& =\frac{\alpha_{n+1}}{1-\beta_{n+1}} f\left(x_{n+1}\right)+\frac{1-\beta_{n+1}-\alpha_{n+1}}{1-\beta_{n+1}} e_{n+1}-\frac{\alpha_{n}}{1-\beta_{n}} f\left(x_{n}\right)-\frac{1-\beta_{n}-\alpha_{n}}{1-\beta_{n}} e_{n} \\
& =\frac{\alpha_{n+1}}{1-\beta_{n+1}}\left(f\left(x_{n+1}\right)-e_{n+1}\right)+\frac{\alpha_{n}}{1-\beta_{n}}\left(e_{n}-f\left(x_{n}\right)\right)+e_{n+1}-e_{n} .
\end{aligned}
$$

It follows that

$$
\left\|l_{n+1}-l_{n}\right\| \leq \frac{\alpha_{n+1}}{1-\beta_{n+1}}\left\|f\left(x_{n+1}\right)-e_{n+1}\right\|+\frac{\alpha_{n}}{1-\beta_{n}}\left\|e_{n}-f\left(x_{n}\right)\right\|+\left\|e_{n+1}-e_{n}\right\| .
$$

Substituting (3.12) into (3.15), we acheive

$$
\left\|l_{n+1}-l_{n}\right\|-\left\|x_{n+1}-x_{n}\right\| \leq \frac{\alpha_{n+1}}{1-\beta_{n+1}}\left\|f\left(x_{n+1}\right)-e_{n+1}\right\|+\frac{\alpha_{n}}{1-\beta_{n}}\left\|e_{n}-f\left(x_{n}\right)\right\| .
$$

It follows from the conditions (ii) and (iii) that

$$
\limsup _{n \rightarrow \infty}\left\|l_{n+1}-l_{n}\right\|-\left\|x_{n+1}-x_{n}\right\| \leq 0 .
$$

From Lemma 2.4, we obtain

$$
\lim _{n \rightarrow \infty}\left\|l_{n}-x_{n}\right\|=0
$$


Fixed Point Theory and Applications

From (3.13), we see

$$
x_{n+1}-x_{n}=\left(1-\beta_{n}\right)\left(l_{n}-x_{n}\right) .
$$

In view of condition (iii), we have

$$
\lim _{n \rightarrow \infty}\left\|x_{n+1}-x_{n}\right\|=0
$$

On the other hand, one has

$$
\begin{aligned}
x_{n+1}-x_{n} & =\alpha_{n} f\left(x_{n}\right)+\beta_{n} x_{n}+\left(1-\alpha_{n}-\beta_{n}\right) e_{n}-x_{n} \\
& =\alpha_{n}\left(f\left(x_{n}\right)-e_{n}\right)+\left(1-\beta_{n}\right)\left(e_{n}-x_{n}\right) .
\end{aligned}
$$

It follows that

$$
\left(1-\beta_{n}\right)\left\|e_{n}-x_{n}\right\| \leq \alpha_{n}\left\|f\left(x_{n}\right)-e_{n}\right\|+\left\|x_{n+1}-x_{n}\right\| .
$$

From conditions (ii), (iii) and (3.20), one sees that

$$
\lim _{n \rightarrow \infty}\left\|e_{n}-x_{n}\right\|=0
$$

Next, we show that $\lim _{n \rightarrow \infty}\left\|u_{n}-x_{n}\right\|=0$.

Letting $p \in \Omega$, we get that $p=K_{r} p$. By Lemma 2.2; that is, $K_{r}$ is firmly nonexpansive, we have

$$
\begin{aligned}
\left\|u_{n}-p\right\|^{2} & =\left\|K_{r} x_{n}-K_{r} p\right\|^{2} \\
& \leq\left\langle K_{r} x_{n}-K_{r} p, J x_{n}-J p\right\rangle \\
& =\left\langle u_{n}-p, J x_{n}-J p\right\rangle \\
& \leq\left\|u_{n}-p\right\|\left\|J x_{n}-J p\right\| \\
& \leq\left\|u_{n}-p\right\|\left\|x_{n}-p\right\| \\
& \leq \frac{1}{2}\left(\left\|u_{n}-p\right\|^{2}+\left\|x_{n}-p\right\|^{2}-\left\|x_{n}-u_{n}\right\|^{2}\right) .
\end{aligned}
$$

It follows that

$$
\left\|u_{n}-p\right\|^{2} \leq\left\|x_{n}-p\right\|^{2}-\left\|x_{n}-u_{n}\right\|^{2} .
$$


Observe that

$$
\begin{aligned}
\left\|v_{n}-p\right\|^{2} & =\left\|J_{\left(M_{1}, \rho_{1}\right)}\left(y_{n}-\rho_{1} A_{1} y_{n}\right)-J_{\left(M_{1}, \rho_{1}\right)}\left(p-\rho_{1} A_{1} p\right)\right\|^{2} \\
& \leq\left\|\left(y_{n}-\rho_{1} A_{1} y_{n}\right)-\left(p-\rho_{1} A_{1} p\right)\right\|^{2} \\
& \leq\left\|y_{n}-p\right\|^{2} \\
& =\left\|J_{\left(M_{2}, \rho_{2}\right)}\left(u_{n}-\rho_{2} A_{2} u_{n}\right)-J_{\left(M_{2}, \rho_{2}\right)}\left(p-\rho_{2} A_{2} p\right)\right\|^{2} \\
& \leq\left\|\left(u_{n}-\rho_{2} A_{2} u_{n}\right)-\left(p-\rho_{2} A_{2} p\right)\right\|^{2} \\
& \leq\left\|u_{n}-p\right\|^{2} .
\end{aligned}
$$

From (3.25) and (3.26), we have

$$
\begin{aligned}
\left\|e_{n}-p\right\|^{2} & =\left\|\mu_{1} S_{k} x_{n}+\left(1-\mu_{1}\right) v_{n}-p\right\|^{2} \\
& \leq \mu_{1}\left\|S_{k} x_{n}-p\right\|^{2}+\left(1-\mu_{1}\right)\left\|v_{n}-p\right\|^{2} \\
& \leq \mu_{1}\left\|x_{n}-p\right\|^{2}+\left(1-\mu_{1}\right)\left\|u_{n}-p\right\|^{2} \\
& \leq \mu_{1}\left\|x_{n}-p\right\|^{2}+\left(1-\mu_{1}\right)\left(\left\|x_{n}-p\right\|^{2}-\left\|x_{n}-u_{n}\right\|^{2}\right) \\
& =\left\|x_{n}-p\right\|^{2}-\left(1-\mu_{1}\right)\left\|x_{n}-u_{n}\right\|^{2} .
\end{aligned}
$$

From (3.1) and (3.27), we obtain

$$
\begin{aligned}
\left\|x_{n+1}-p\right\|^{2} & =\left\|\alpha_{n} f\left(x_{n}\right)+\beta_{n} x_{n}+\left(1-\alpha_{n}-\beta_{n}\right) e_{n}-p\right\|^{2} \\
& \leq \alpha_{n}\left\|f\left(x_{n}\right)-p\right\|^{2}+\beta_{n}\left\|x_{n}-p\right\|^{2}+\left(1-\alpha_{n}-\beta_{n}\right)\left\|e_{n}-p\right\|^{2} \\
& \leq \alpha_{n}\left\|f\left(x_{n}\right)-p\right\|^{2}+\beta_{n}\left\|x_{n}-p\right\|^{2}+\left(1-\alpha_{n}-\beta_{n}\right)\left\{\left\|x_{n}-p\right\|^{2}-\left(1-\mu_{1}\right)\left\|x_{n}-u_{n}\right\|^{2}\right\} \\
& \leq \alpha_{n}\left\|f\left(x_{n}\right)-p\right\|^{2}+\left(1-\alpha_{n}\right)\left\|x_{n}-p\right\|^{2}-\left(1-\alpha_{n}-\beta_{n}\right)\left(1-\mu_{1}\right)\left\|x_{n}-u_{n}\right\|^{2} \\
& \leq \alpha_{n}\left\|f\left(x_{n}\right)-p\right\|^{2}+\left\|x_{n}-p\right\|^{2}-\left(1-\alpha_{n}-\beta_{n}\right)\left(1-\mu_{1}\right)\left\|x_{n}-u_{n}\right\|^{2} .
\end{aligned}
$$

It follows that

$$
\left(1-\alpha_{n}-\beta_{n}\right)\left(1-\mu_{1}\right)\left\|x_{n}-u_{n}\right\|^{2} \leq \alpha_{n}\left\|f\left(x_{n}\right)-p\right\|^{2}+\left\|x_{n+1}-x_{n}\right\|\left(\left\|x_{n}-p\right\|+\left\|x_{n+1}-p\right\|\right) .
$$

From (i)-(iii), $\mu_{1} \in[0,1)$, and $\left\|x_{n+1}-x_{n}\right\| \rightarrow 0$ as $n \rightarrow \infty$, we have

$$
\lim _{n \rightarrow \infty}\left\|x_{n}-u_{n}\right\|=0
$$


Fixed Point Theory and Applications

Next, we prove that

$$
p \in \Omega:=F(S) \cap F\left(J_{\left(M_{1}, \rho_{1}\right)}\left(I-\rho_{1} A_{1}\right) J_{\left(M_{2}, \rho_{2}\right)}\left(I-\rho_{2} A_{2}\right)\right) \cap \operatorname{GMEP}(F, \varphi, B) .
$$

(i) We will show that $p \in \operatorname{GMEP}(F, \varphi, B)$.

Since $J$ is uniformly norm-to-norm continuous on bounded sets, we have

$$
\lim _{n \rightarrow \infty}\left\|J x_{n}-J u_{n}\right\|=0
$$

We obtain

$$
\lim _{n \rightarrow \infty} \frac{\left\|J x_{n}-J u_{n}\right\|}{r}=0
$$

Noticing that $u_{n}=K_{r} x_{n}$, we have

$$
H\left(u_{n}, y\right)+\frac{1}{r}\left\langle y-u_{n}, J u_{n}-J x_{n}\right\rangle \geq 0, \quad \forall y \in C .
$$

From (A2), we note that

$$
\left\|y-u_{n}\right\| \frac{\left\|J u_{n}-J x_{n}\right\|}{r} \geq \frac{1}{r}\left\langle y-u_{n}, J u_{n}-J x_{n}\right\rangle \geq-H\left(u_{n}, y\right) \geq H\left(y, u_{n}\right), \quad \forall y \in C .
$$

Taking the limit as $n \rightarrow \infty$ in the above inequality, from (A4) and $u_{n} \rightarrow p$, we have $H(y, p) \leq 0, y \in C$. For $0<t<1$ and $y \in C$, define $y_{t}=t y+(1-t) p$. Noticing that $y, p \in C$, we obtain $y_{t} \in C$, which yields $H\left(y_{t}, p\right) \leq 0$. It follows from (A1) that

$$
0=H\left(y_{t}, y_{t}\right) \leq t H\left(y_{t}, y\right)+(1-t) H\left(y_{t}, p\right) \leq t H\left(y_{t}, y\right)
$$

that is, $H\left(y_{t}, y\right) \geq 0$. $\varphi, B)$.

Let $t \downarrow 0$; from (A3), we obtain $H(p, y) \geq 0, y \in C$. This implies that $p \in \operatorname{GMEP}(F$,

(ii) Next, we will show that $p \in F(S) \cap F\left(J_{\left(M_{1}, \rho_{1}\right)}\left(I-\rho_{1} A_{1}\right) J_{\left(M_{2}, \rho_{2}\right)}\left(I-\rho_{2} A_{2}\right)\right)$.

Define a mapping $G: E \rightarrow E$ by

$$
G x=\mu_{1} S_{k} x+\left(1-\mu_{1}\right) J_{\left(M_{1}, \rho_{1}\right)}\left(I-\rho_{1} A_{1}\right) J_{\left(M_{2}, \rho_{2}\right)}\left(I-\rho_{2} A_{2}\right) x, \quad x \in E .
$$

From Lemma 2.9, we see that $G$ is nonexpansive mapping such that

$$
F(G)=F(S) \cap F\left(J_{\left(M_{1}, \rho_{1}\right)}\left(I-\rho_{1} A_{1}\right) J_{\left(M_{2}, \rho_{2}\right)}\left(I-\rho_{2} A_{2}\right)\right) .
$$

It follows from Lemma 2.10 that $p \in F(G)=F(S) \cap F\left(J_{\left(M_{1}, \rho_{1}\right)}\left(I-\rho_{1} A_{1}\right) J_{\left(M_{2}, \rho_{2}\right)}\left(I-\rho_{2} A_{2}\right)\right)$. 
We define a mapping $\bar{G}: E \rightarrow E$ by $\bar{G} x=\sigma G x+(1-\sigma) K_{r} x, x \in E, \sigma \in(0,1)$.

Again from Lemma 2.9 , we see that $\bar{G}$ is nonexpansive mapping such that

$$
\begin{aligned}
F(\bar{G}) & =F(G) \cap \operatorname{GMEP}(F, \varphi, B) \\
& =F(S) \cap F\left(J_{\left(M_{1}, \rho_{1}\right)}\left(I-\rho_{1} A_{1}\right) J_{\left(M_{2}, \rho_{2}\right)}\left(I-\rho_{2} A_{2}\right)\right) \cap \operatorname{GMEP}(F, \varphi, B) .
\end{aligned}
$$

Hence, $p \in \Omega$. Next, we show that $\limsup _{n \rightarrow \infty}\left\langle f(\bar{x})-\bar{x}, J\left(x_{n}-\bar{x}\right)\right\rangle \leq 0$, where $\bar{x}=P_{\Omega} f(\bar{x})$. Since $\left\{x_{n}\right\}$ is bounded, we can choose a sequence $\left\{x_{n_{i}}\right\}$ of $\left\{x_{n}\right\}$ which $x_{n_{i}} \rightarrow p$ such that

$$
\limsup _{n \rightarrow \infty}\left\langle f(\bar{x})-\bar{x}, J\left(x_{n}-\bar{x}\right)\right\rangle=\lim _{i \rightarrow \infty}\left\langle f(\bar{x})-\bar{x}, J\left(x_{n_{i}}-\bar{x}\right)\right\rangle
$$

Now, from (3.40) and Proposition 2.7(iii) and since $J$ is strong to weak* uniformly continuous on bounded subset of $E$, we have

$$
\begin{aligned}
\limsup _{n \rightarrow \infty}\left\langle f(\bar{x})-\bar{x}, J\left(x_{n}-\bar{x}\right)\right\rangle & =\lim _{i \rightarrow \infty}\left\langle f(\bar{x})-\bar{x}, J\left(x_{n_{i}}-\bar{x}\right)\right\rangle \\
& =\langle f(\bar{x})-\bar{x}, J(p-\bar{x})\rangle \leq 0 .
\end{aligned}
$$

From (3.20), it follows that

$$
\limsup _{n \rightarrow \infty}\left\langle f(\bar{x})-\bar{x}, J\left(x_{n+1}-\bar{x}\right)\right\rangle \leq 0
$$

Finally, we show that $x_{n} \rightarrow \bar{x}$ as $n \rightarrow \infty$.

Notice that

$$
\begin{aligned}
\left\|x_{n+1}-\bar{x}\right\|^{2}= & \left\|\alpha_{n}\left(f\left(x_{n}\right)-\bar{x}\right)+\beta_{n}\left(x_{n}-\bar{x}\right)+\left(1-\alpha_{n}-\beta_{n}\right)\left(e_{n}-\bar{x}\right)\right\|^{2} \\
\leq & \left\|\beta_{n}\left(x_{n}-\bar{x}\right)+\left(1-\alpha_{n}-\beta_{n}\right)\left(e_{n}-\bar{x}\right)\right\|^{2}+2 \alpha_{n}\left\langle f\left(x_{n}\right)-\bar{x}, J\left(x_{n+1}-\bar{x}\right)\right\rangle \\
\leq & \left(\beta_{n}\left\|x_{n}-\bar{x}\right\|+\left(1-\alpha_{n}-\beta_{n}\right)\left\|e_{n}-\bar{x}\right\|\right)^{2}+2 \alpha_{n}\left\langle f\left(x_{n}\right)-f(\bar{x}), J\left(x_{n+1}-\bar{x}\right)\right\rangle \\
& +2 \alpha_{n}\left\langle f(\bar{x})-\bar{x}, J\left(x_{n+1}-\bar{x}\right)\right\rangle \\
\leq & \left(\beta_{n}\left\|x_{n}-\bar{x}\right\|+\left(1-\alpha_{n}-\beta_{n}\right)\left\|x_{n}-\bar{x}\right\|^{2}+2 \alpha_{n} \alpha\left\langle x_{n}-\bar{x}, J\left(x_{n+1}-\bar{x}\right)\right\rangle\right. \\
& +2 \alpha_{n}\left\langle f(\bar{x})-\bar{x}, J\left(x_{n+1}-\bar{x}\right)\right\rangle \\
\leq & \left(1-\alpha_{n}\right)^{2}\left\|x_{n}-\bar{x}\right\|^{2}+\alpha_{n} \alpha\left(\left\|x_{n}-\bar{x}\right\|^{2}+\left\|x_{n+1}-\bar{x}\right\|^{2}\right) \\
& +2 \alpha_{n}\left\langle f(\bar{x})-\bar{x}, J\left(x_{n+1}-\bar{x}\right)\right\rangle,
\end{aligned}
$$


which implies that

$$
\begin{aligned}
\left\|x_{n+1}-\bar{x}\right\|^{2} \leq & \frac{\left(1-\alpha_{n}\right)^{2}+\alpha_{n} \alpha}{1-\alpha_{n} \alpha}\left\|x_{n}-\bar{x}\right\|^{2}+\frac{2 \alpha_{n}}{1-\alpha_{n} \alpha}\left\langle f(\bar{x})-\bar{x}, J\left(x_{n+1}-\bar{x}\right)\right\rangle \\
\leq & {\left[1-\frac{2 \alpha_{n}(1-\alpha)}{1-\alpha_{n} \alpha}\right]\left\|x_{n}-\bar{x}\right\|^{2}+\frac{2 \alpha_{n}(1-\alpha)}{1-\alpha_{n} \alpha} } \\
& \times\left(\frac{1}{(1-\alpha)}\left\langle f(\bar{x})-\bar{x}, J\left(x_{n+1}-\bar{x}\right)\right\rangle+\frac{\alpha_{n}}{2(1-\alpha)} M_{2}\right),
\end{aligned}
$$

where $M_{2}$ is an appropriate constant such that $M_{2} \geq \sup _{n>1}\left\{\left\|x_{n}-\bar{x}\right\|^{2}\right\}$.

Set $b_{n}=2 \alpha_{n}(1-\alpha) /\left(1-\alpha_{n} \alpha\right)$ and $c_{n}=(1 /(1-\alpha))\left\langle f(\bar{x})-\bar{x}, J\left(x_{n+1}-\bar{x}\right)\right\rangle+\left(\alpha_{n} / 2(1-\alpha)\right) M_{2}$.

Then, we have

$$
\left\|x_{n+1}-\bar{x}\right\|^{2} \leq\left(1-b_{n}\right)\left\|x_{n}-\bar{x}\right\|^{2}+b_{n} c_{n}, \quad \forall n \geq 0 .
$$

From condition (ii) and (3.42), we see that

$$
\lim _{n \rightarrow \infty} b_{n}=0, \quad \sum_{n=0}^{\infty} b_{n}=\infty, \quad \limsup _{n \rightarrow \infty} c_{n} \leq 0 .
$$

Therefore, applying Lemma 2.3 to (3.45), we have

$$
\lim _{n \rightarrow \infty}\left\|x_{n}-\bar{x}\right\|=0
$$

This completes the proof.

Using Theorem 3.1, we obtain the following corollaries.

Corollary 3.2. Let E be a uniformly convex and 2-uniformly smooth Banach space with the smooth constant $K$. Let $M_{i}: E \rightarrow 2^{E}$ be a maximal monotone mapping, and let $A_{i}: E \rightarrow E$ be a $\gamma_{i}$-inverse strongly accretive mapping, respectively, for each $i=1,2$. Let $F$ be a bifunction of $C \times C$ into real numbers $\mathbb{R}$ satisfying (A1)-(A4). Let $f$ be a contraction of $E$ into itself with coefficient $\alpha \in(0,1)$. Let $S: E \rightarrow E$ be an $\lambda$-strict pseudocontraction with a fixed point. Define a mapping $S_{k}$ by $S_{k} x=$ $k x+(1-k) S x$, for all $x \in E$. Assume that $\Omega:=F(S) \cap F(\widetilde{Q}) \cap E P(F) \neq \emptyset$, where $\widetilde{Q}$ is defined as Lemma 1.3. Let $\left\{x_{n}\right\}$ be a sequence generated by $x_{1} \in E$ and

$$
\begin{gathered}
F\left(u_{n}, y\right)+\frac{1}{r}\left\langle y-u_{n}, J u_{n}-J x_{n}\right\rangle \geq 0, \quad \forall y \in C, \\
y_{n}=J_{M_{2}, \rho_{2}}\left(u_{n}-\rho_{2} A_{2} u_{n}\right), \\
v_{n}=J_{M_{1}, \rho_{1}}\left(y_{n}-\rho_{1} A_{1} y_{n}\right), \\
x_{n+1}=\alpha_{n} f\left(x_{n}\right)+\beta_{n} x_{n}+\gamma_{n}\left[\mu_{1} S_{k} x_{n}+\left(1-\mu_{1}\right) v_{n}\right],
\end{gathered}
$$


for every $n \geq 1$, where $\left\{\alpha_{n}\right\},\left\{\beta_{n}\right\}$, and $\left\{\gamma_{n}\right\}$ are sequences in $[0,1], \mu_{1} \in[0,1), \rho_{1} \in\left(0, \gamma_{1} / K^{2}\right]$, $\rho_{2} \in\left(0, \gamma_{2} / K^{2}\right]$, and $r>0$. If the control sequences satisfy the following restrictions:

(i) $\alpha_{n}+\beta_{n}+\gamma_{n}=1$,

(ii) $\sum_{n=0}^{\infty} \alpha_{n}=\infty$ and $\lim _{n \rightarrow \infty} \alpha_{n}=0$,

(iii) $0<\liminf _{n \rightarrow \infty} \beta_{n} \leq \lim \sup _{n \rightarrow \infty} \beta_{n}<1$,

then $\left\{x_{n}\right\}$ converges strongly to $\bar{x}=P_{\Omega} f(\bar{x})$, where $P_{\Omega}$ is the sunny nonexpansive retraction from $E$ onto $\Omega$ and $(\bar{x}, \bar{y})$ is a solution to the problem (1.6), where $\bar{y}=J_{\left(M_{2}, \rho_{2}\right)}\left(\bar{x}-\rho_{2} A_{2} \bar{x}\right)$.

Proof. Put $B=\varphi=0$, in Theorem 3.1. The conclusion of Corollary 3.2 can be obtained with the desired result easily.

Corollary 3.3. Let E be a uniformly convex and 2-uniformly smooth Banach space with the smooth constant $K$. Let $M_{i}: E \rightarrow 2^{E}$ be a maximal monotone mapping, and let $A_{i}: E \rightarrow E$ be a $\gamma_{i^{-}}$ inverse strongly accretive mapping, respectively, for each $i=1,2$. Let $S: E \rightarrow E$ be a $\lambda$-strict pseudocontraction with a fixed point, and let $f$ be a contraction of $E$ into itself with coefficient $\alpha \in$ $(0,1)$. Define a mapping $S_{k}$ by $S_{k} x=k x+(1-k) S x, \forall x \in E$. Assume that $\Omega:=F(S) \cap F(\tilde{Q}) \neq \emptyset$, where $\widetilde{Q}$ is defined as in Lemma 1.3. Let $\left\{x_{n}\right\}$ be a sequence generated by $x_{1} \in E$ and

$$
\begin{gathered}
y_{n}=J_{M_{2}, \rho_{2}}\left(x_{n}-\rho_{2} A_{2} x_{n}\right), \\
v_{n}=J_{M_{1}, \rho_{1}}\left(y_{n}-\rho_{1} A_{1} y_{n}\right), \\
x_{n+1}=\alpha_{n} f\left(x_{n}\right)+\beta_{n} x_{n}+\gamma_{n}\left[\mu_{1} S_{k} x_{n}+\left(1-\mu_{1}\right) v_{n}\right],
\end{gathered}
$$

for every $n \geq 1$, where $\left\{\alpha_{n}\right\},\left\{\beta_{n}\right\}$, and $\left\{\gamma_{n}\right\}$ are sequences in $[0,1], \mu_{1} \in[0,1), \rho_{1} \in\left(0, \gamma_{1} / K^{2}\right]$, $\rho_{2} \in\left(0, \gamma_{2} / K^{2}\right]$. If the control sequences satisfy the following restrictions:

(i) $\alpha_{n}+\beta_{n}+\gamma_{n}=1$,

(ii) $\sum_{n=0}^{\infty} \alpha_{n}=\infty$ and $\lim _{n \rightarrow \infty} \alpha_{n}=0$,

(iii) $0<\liminf _{n \rightarrow \infty} \beta_{n} \leq \lim \sup _{n \rightarrow \infty} \beta_{n}<1$,

then $\left\{x_{n}\right\}$ converges strongly to $\bar{x}=P_{\Omega} f(\bar{x})$, where $P_{\Omega}$ is the sunny nonexpansive retraction from $E$ onto $\Omega$ and $(\bar{x}, \bar{y})$ is a solution to the problem (1.6), where $\bar{y}=J_{\left(M_{2}, \rho_{2}\right)}\left(\bar{x}-\rho_{2} A_{2} \bar{x}\right)$.

Proof. Put $F(x, y)=0$, for all $x, y \in C$, and $B=\varphi=0$, in Theorem 3.1. The conclusion of Corollary 3.3 can be obtained with the desired result easily.

Remark 3.4. Corollary 3.3 extends and improves the results in [31].

Corollary 3.5. Let E be a uniformly convex and 2-uniformly smooth Banach space with the smooth constant $K$. Let $M: E \rightarrow 2^{E}$ be a maximal monotone mapping, and let $A: E \rightarrow E$ be a $\gamma$-inversestrongly accretive mapping. Let $S: E \rightarrow E$ be a $\lambda$-strict pseudocontraction with a fixed point. Define a mapping $S_{k}$ by $S_{k} x=k x+(1-k) S$, for all $x \in E$. Assume that $\Omega:=F(S) \cap S V I(E, A, M) \neq \emptyset$. Let $\left\{x_{n}\right\}$ be a sequence generated by $x_{1}=u \in E$ and

$$
\begin{gathered}
y_{n}=J_{M, \rho}\left(x_{n}-\rho A x_{n}\right), \\
v_{n}=J_{M, \rho}\left(y_{n}-\rho A y_{n}\right), \\
x_{n+1}=\alpha_{n} u+\beta_{n} x_{n}+\gamma_{n}\left[\mu_{1} S_{k} x_{n}+\left(1-\mu_{1}\right) v_{n}\right],
\end{gathered}
$$


for every $n \geq 1$, where $\left\{\alpha_{n}\right\},\left\{\beta_{n}\right\}$, and $\left\{\gamma_{n}\right\}$ are sequences in $[0,1], \mu_{1} \in[0,1), \rho \in\left(0, \gamma / K^{2}\right]$. If the control sequences satisfy the following restrictions:

(i) $\alpha_{n}+\beta_{n}+\gamma_{n}=1$,

(ii) $\sum_{n=0}^{\infty} \alpha_{n}=\infty$ and $\lim _{n \rightarrow \infty} \alpha_{n}=0$,

(iii) $0<\liminf _{n \rightarrow \infty} \beta_{n} \leq \lim \sup _{n \rightarrow \infty} \beta_{n}<1$,

then $\left\{x_{n}\right\}$ converges strongly to $\bar{x}=P_{\Omega} u$, where $P_{\Omega}$ is the sunny nonexpansive retraction from $E$ onto $\Omega$ and $(\bar{x}, \bar{y})$ is a solution to the problem $(1.7)$, where $\bar{y}=J_{(M, \rho)}(\bar{x}-\rho A \bar{x})$.

Proof. Put $F(x, y)=0$, for all $x, y \in C, B=\varphi=0, M_{1}=M_{2}=M, A_{1}=A_{2}=A$, and $f(x)=u$ for all $x \in E$ in Theorem 3.1. The conclusion of Corollary 3.5 can be obtained with the desired result easily.

\section{Acknowledgments}

This research is supported by the Centre of Excellence in Mathematics, the Commission on Higher Education, Thailand. Also, the authors would like to thank the referees for their careful readings and valuable suggestions to improve the writing of this paper.

\section{References}

[1] E. Blum and W. Oettli, "From optimization and variational inequalities to equilibrium problems," The Mathematics Student, vol. 63, no. 1-4, pp. 123-145, 1994.

[2] L.-C. Ceng and J.-C. Yao, "A hybrid iterative scheme for mixed equilibrium problems and fixed point problems," Journal of Computational and Applied Mathematics, vol. 214, no. 1, pp. 186-201, 2008.

[3] Y. J. Cho, X. Qin, and J. I. Kang, "Convergence theorems based on hybrid methods for generalized equilibrium problems and fixed point problems," Nonlinear Analysis: Theory, Methods \& Applications, vol. 71, no. 9, pp. 4203-4214, 2009.

[4] C. Jaiboon and P. Kumam, "A general iterative method for addressing mixed equilibrium problems and optimization problems," Nonlinear Analysis: Theory, Methods E Applications, vol. 73, no. 5, pp. 1180-1202, 2010.

[5] T. Jitpeera and P. Kumam, "An extragradient type method for a system of equilibrium problems, variational inequality problems and fixed points of finitely many nonexpansive mappings," Journal of Nonlinear Analysis and Optimization: Theory \& Applications, vol. 1, no. 1, pp. 71-91, 2010.

[6] S. D. Flåm and A. S. Antipin, "Equilibrium programming using proximal-like algorithms," Mathematical Programming, vol. 78, no. 1, pp. 29-41, 1997.

[7] P. Kumam, "Strong convergence theorems by an extragradient method for solving variational inequalities and equilibrium problems in a Hilbert space," Turkish Journal of Mathematics, vol. 33, no. 1, pp. 85-98, 2009.

[8] P. Kumam, "A hybrid approximation method for equilibrium and fixed point problems for a monotone mapping and a nonexpansive mapping," Nonlinear Analysis: Hybrid Systems, vol. 2, no. 4, pp. 1245-1255, 2008.

[9] P. Kumam, "A relaxed extragradient approximation method of two inverse-strongly monotone mappings for a general system of variational inequalities, fixed point and equilibrium problems," Bulletin of the Iranian Mathematical Society, vol. 36, no. 1, pp. 227-250, 2010.

[10] P. Kumam, "A new hybrid iterative method for solution of equilibrium problems and fixed point problems for an inverse strongly monotone operator and a nonexpansive mapping," Journal of Applied Mathematics and Computing, vol. 29, no. 1-2, pp. 263-280, 2009.

[11] P. Kumam and P. Katchang, "A viscosity of extragradient approximation method for finding equilibrium problems, variational inequalities and fixed point problems for nonexpansive mappings," Nonlinear Analysis: Hybrid Systems, vol. 3, no. 4, pp. 475-486, 2009. 
[12] W. Kumam and P. Kumam, "Hybrid iterative scheme by a relaxed extragradient method for solutions of equilibrium problems and a general system of variational inequalities with application to optimization," Nonlinear Analysis: Hybrid Systems, vol. 3, no. 4, pp. 640-656, 2009.

[13] P. Katchang, Y. Khamlae, and P. Kumam, "A viscosity iterative scheme for inverse-strongly accretive operators in Banach spaces," Journal of Computational Analysis and Applications, vol. 12, no. 3, pp. 678686, 2010.

[14] W. Kumam, C. Jaiboon, P. Kumam, and A. Singta, "A shrinking projection method for generalized mixed equilibrium problems, variational inclusion problems and a finite family of quasinonexpansive mappings," Journal of Inequalities and Applications, vol. 2010, Article ID 458247, 25 pages, 2010.

[15] A. Moudafi and M. Théra, "Proximal and dynamical approaches to equilibrium problems," in IllPosed Variational Problems and Regularization Techniques (Trier, 1998), vol. 477 of Lecture Notes in Econom. and Math. Systems, pp. 187-201, Springer, Berlin, Germany, 1999.

[16] X. Qin, Y. J. Cho, and S. M. Kang, "Viscosity approximation methods for generalized equilibrium problems and fixed point problems with applications," Nonlinear Analysis: Theory, Methods $\mathcal{E}$ Applications, vol. 72, no. 1, pp. 99-112, 2010.

[17] X. Qin, Y. J. Cho, and S. M. Kang, "Convergence theorems of common elements for equilibrium problems and fixed point problems in Banach spaces," Journal of Computational and Applied Mathematics, vol. 225, no. 1, pp. 20-30, 2009.

[18] S. Saewan and P. Kumam, "Modified hybrid block iterative algorithm for convex feasibility problems and generalized equilibrium problems for uniformly quasi- $\phi$-asymptotically nonexpansive mappings," Abstract and Applied Analysis, vol. 2010, Article ID 357120, 22 pages, 2010.

[19] S. Saewan and P. Kumam, "A hybrid iterative scheme for a maximal monotone operator and two countable families of relatively quasi-nonexpansive mappings for generalized mixed equilibrium and variational inequality problems," Abstract and Applied Analysis, vol. 2010, Article ID 123027, 31 pages, 2010.

[20] S. Saewan, P. Kumam, and K. Wattanawitoon, "Convergence theorem based on a new hybrid projection method for finding a common solution of generalized equilibrium and variational inequality problems in Banach spaces," Abstract and Applied Analysis, vol. 2010, Article ID 734126, 26 pages, 2010.

[21] S. Takahashi and W. Takahashi, "Strong convergence theorem for a generalized equilibrium problem and a nonexpansive mapping in a Hilbert space," Nonlinear Analysis: Theory, Methods E Applications, vol. 69, no. 3, pp. 1025-1033, 2008.

[22] Y. Yao, Y. J. Cho, and R. Chen, “An iterative algorithm for solving fixed point problems, variational inequality problems and mixed equilibrium problems," Nonlinear Analysis: Theory, Methods $\mathcal{E}$ Applications, vol. 71, no. 7-8, pp. 3363-3373, 2009.

[23] S.-S. Zhang, J. H. W. Lee, and C. K. Chan, "Algorithms of common solutions to quasi variational inclusion and fixed point problems," Applied Mathematics and Mechanics, vol. 29, no. 5, pp. 571-581, 2008.

[24] K. Aoyama, H. Iiduka, and W. Takahashi, "Weak convergence of an iterative sequence for accretive operators in Banach spaces," Fixed Point Theory and Applications, vol. 2006, Article ID 35390, 13 pages, 2006.

[25] L.-C. Ceng, C.-Y. Wang, and J.-C. Yao, "Strong convergence theorems by a relaxed extragradient method for a general system of variational inequalities," Mathematical Methods of Operations Research, vol. 67, no. 3, pp. 375-390, 2008.

[26] X. Qin, S. Y. Cho, and S. M. Kang, "Convergence of an iterative algorithm for systems of variational inequalities and nonexpansive mappings with applications," Journal of Computational and Applied Mathematics, vol. 233, no. 2, pp. 231-240, 2009.

[27] Y. Yao, M. Aslam Noor, K. Inayat Noor, Y.-C. Liou, and H. Yaqoob, “Modified extragradient methods for a system of variational inequalities in Banach spaces," Acta Applicandae Mathematicae, vol. 110, no. 3, pp. 1211-1224, 2010.

[28] F. E. Browder, "Fixed-point theorems for noncompact mappings in Hilbert space," Proceedings of the National Academy of Sciences of the United States of America, vol. 53, pp. 1272-1276, 1965.

[29] S. Reich, "Strong convergence theorems for resolvents of accretive operators in Banach spaces," Journal of Mathematical Analysis and Applications, vol. 75, no. 1, pp. 287-292, 1980.

[30] P. Katchang and P. Kumam, "An iterative algorithm for finding a common solution of fixed points and a general system of variational inequalities for two inverse strongly accretive operators," Positivity. In press. 
[31] X. Qin, S. S. Chang, Y. J. Cho, and S. M. Kang, "Approximation of solutions to a system of variational inclusions in Banach spaces," Journal of Inequalities and Applications, vol. 2010, Article ID 916806, 16 pages, 2010.

[32] X. Qin, S.-S. Chang, and Y. J. Cho, "Iterative methods for generalized equilibrium problems and fixed point problems with applications," Nonlinear Analysis: Real World Applications, vol. 11, no. 4, pp. 29632972, 2010.

[33] W. Takahashi and K. Zembayashi, "Strong and weak convergence theorems for equilibrium problems and relatively nonexpansive mappings in Banach spaces," Nonlinear Analysis: Theory, Methods $\mathcal{E}$ Applications, vol. 70, no. 1, pp. 45-57, 2009.

[34] P. L. Combettes and S. A. Hirstoaga, "Equilibrium programming in Hilbert spaces," Journal of Nonlinear and Convex Analysis, vol. 6, no. 1, pp. 117-136, 2005.

[35] S.-S. Zhang, "Generalized mixed equilibrium problem in Banach spaces," Applied Mathematics and Mechanics, vol. 30, no. 9, pp. 1105-1112, 2009.

[36] N. Petrot, K. Wattanawitoon, and P. Kumam, "A hybrid projection method for generalized mixed equilibrium problems and fixed point problems in Banach spaces," Nonlinear Analysis: Hybrid Systems, vol. 4, no. 4, pp. 631-643, 2010.

[37] H.-K. Xu, "Iterative algorithms for nonlinear operators," Journal of the London Mathematical Society, vol. 66, no. 1, pp. 240-256, 2002.

[38] T. Suzuki, "Strong convergence of Krasnoselskii and Mann's type sequences for one-parameter nonexpansive semigroups without Bochner integrals," Journal of Mathematical Analysis and Applications, vol. 305, no. 1, pp. 227-239, 2005.

[39] S. Reich, "Asymptotic behavior of contractions in Banach spaces," Journal of Mathematical Analysis and Applications, vol. 44, pp. 57-70, 1973.

[40] S. Kitahara and W. Takahashi, "Image recovery by convex combinations of sunny nonexpansive retractions," Topological Methods in Nonlinear Analysis, vol. 2, no. 2, pp. 333-342, 1993.

[41] H.-K. Xu, "Inequalities in Banach spaces with applications," Nonlinear Analysis: Theory, Methods $\mathcal{E}$ Applications, vol. 16, no. 12, pp. 1127-1138, 1991. 